\title{
Studies About Degradation of Zirconia in Artificial Saliva
}

\begin{abstract}
SABINA DAVID ${ }^{1}$, IOAN SARBU ${ }^{1}$, MIH AI COSMIN COTRUT ${ }^{2}$, RALUCA MONICA COMANEANU ${ }^{3 *}$, MIREL STOIAN ${ }^{3}$, DAN NICOLAE PATROI ${ }^{3}$

${ }^{1}$ University of Medicine and Pharmacy Carol Davila, Faculty of Dental Medicine, 17-23 Calea Plevnei, 010221, Bucharest, Romania 2Politehnica University of Bucharest, Materials Science and Engineering Faculty, 313 Splaiul Independentei, 060042, Bucharest, Romania

${ }^{3}$ Titu Maiorescu University of Bucharest, Faculty of Dental Medicine, 67A Ghe. Petrascu, 031593, Bucharest, Romania

To study zirconia degradation, we used samples with $16.5 \mathrm{~mm}$ diameter and $3 \mathrm{~mm}$ thick, milled from IPS e.max Zir CAD disks and subjected to sintering. Samples were immersed in Fusayama Meyer artificial saliva, removed after one day, 3 days, 7 days, 14 days and 21 days and examined from the point of view of surface morphology and elemental composition with an electronic scanning microscope. By SEM examining of samples prior to immersion in artificial saliva we found that the material contained strictly the chemical elements specified by the manufacturer. SEM examination and mass evaluations performed after immersion in artificial saliva demonstrate that the material did not suffer degradation processes, the minimum differences in the measurements being within the analytical balance weighing range.
\end{abstract}

Keywords: zirconia, artificial saliva, degradation

The low-temperature degradation of zirconia, also known as aging, is produced by a slow surface transformation of metastable tetragonal crystals in a stable monoclinic structure in the presence of water or vapors of water. [1] A certain degree of transformation in this sense is beneficial for improving the physical properties of the material.

How ever, there is a narrow boundarybetween improving and destroying mechanical properties, because accelerating the aging process leads to deterioration of properties [2]. The transformation initially starts with a corrosion mechanism, inside the granules on the surface of the material, by the isolated increase in granule volume, pushing neighboring granules, producing microfishers that allow penetration of water and phase destabilization [3].

Experimental observations have shown that degradation occurs most rapidly at temperatures between 200 and 300 ${ }^{\circ} \mathrm{C}$ and is time dependent [1].

The aging process depends on a number of features of the microstructure, such as [1]:

- porosity,

- residual stress,

- size of the granules

- the stabilizer content of the processed material.

The critical granule's size reported in the literature [1] is between 0.2 and $1 \mu \mathrm{m}$, depending on the $\mathrm{Y}_{2} \mathrm{O}_{3}$ content.

The presence of granules larger than $1^{2} \mu \mathrm{m}$ suffers a more pronounced transformation from the tetragonal to the monoclinic phase, associated with a significant decrease in resistance, while the granules smaller than $0.4 \mu \mathrm{m}$ did not show a significant change in phase content or resistance [1].

It has also been found that at a granule size below 0.2 $\mu \mathrm{m}$, tetragonal-monoclinic transformation is not possible which can lead to a reduction in tear strength [1].
An in vitro study [4] which investigating the effect of aging on zirconia used in oral rehabilitation has found that, although the aging process reduces the mechanical characteristics of zirconia, the decrease occurs within clinically acceptable values.

To assess the degree of degradation of ceramics in different solutions, it is not possible to use electrochemical techniques, it is preferable to immerse the samples under similar conditions to the environment in which the materials are used.

\section{Experimental part}

To study zirconia degradation, we used samples with $16.5 \mathrm{~mm}$ diameter and $3 \mathrm{~mm}$ thick, milled from IPS e. $\mathrm{max}$ Zir CAD disks and subjected to sintering.

Samples were immersed in Fusayama Meyer artificial saliva $\left(0.4 \mathrm{gl}^{-1} \mathrm{NaCl}, 0.9 \mathrm{gl}^{-1} \mathrm{KCl}, 1 \mathrm{gl}^{-1}\right.$ uree, $0.69 \mathrm{~g}^{-1} \mathrm{NaH}_{2} \mathrm{PO}$, $\left.0.795 \mathrm{gl}^{-1} \mathrm{CaCl} * 2 \mathrm{H}_{2} \mathrm{O}\right)$ at $\mathrm{pH} 5.2$ maintained at $37 \pm 0.1^{\circ} \mathrm{C}$ by a Memmert IF55 incubator.

Zirconia samples were examined before immersion in artificial saliva from the point of view of surface morphology and elemental composition with an electronic scanning microscope (SEM) equipped with an energy dispersion spectrometer - EDS (Phenom ProX model, manufacturer from PhenomWorld, Netherlands).

Before the immersion tests were performed, the samples were sonicated for $20 \mathrm{~min}$ in acetone to be degreased and cleaned with impurities and then rinsed with ultrapure water (ASTM I type).

We used 5 discs to track their mass in pre-established time ranges: one day, 3 days, 7 days, 14 days and 21 days. For this purpose we used a Kern ALT 100-5AM balance with an accuracy of $0.01 \mathrm{mg}$.

Samples were removed from artificial saliva at predetermined ranges, cleaned with deionized water, dried for one hour in a Memmert UF55 oven, and then stored 72

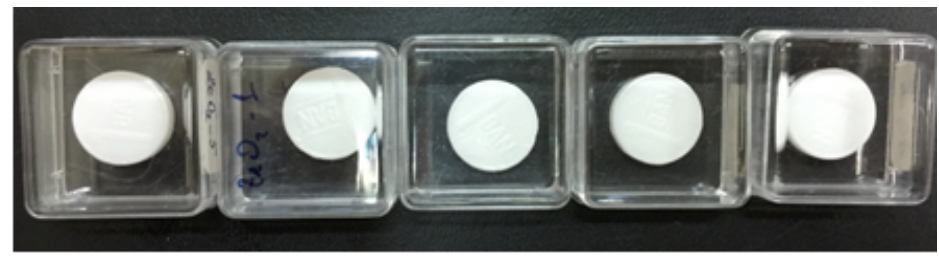

Fig. 1.Experimental samples - zirconia discs 
hours in the desiccator before being weighed. Their mass measurements after the immersion tests were repeated 5 times for the best accuracy of the results.

\section{Results and discussions}

The elemental composition obtained by analyzing one of the zirconia disks is shown in table 1 , and figure 2 illustrates the EDS spectrum corresponding to the compositional analysis.

Images of zirconia surface morphology at different magnification powers can be found in figure 3 .

\begin{tabular}{|c|c|c|c|}
\hline \multirow{2}{*}{ No. } & \multirow{2}{*}{ Element } & \multicolumn{2}{|c|}{ Concentration } \\
\cline { 3 - 4 } & & $\mathbf{a t} \%$ & $\mathbf{w t} \%$ \\
\hline 1 & $\mathrm{O}$ & 59.59 & 20.21 \\
\hline 2 & $\mathrm{Zr}$ & 35.08 & 67.84 \\
\hline 3 & $\mathrm{Y}$ & 3.45 & 6.51 \\
\hline 4 & $\mathrm{Hf}$ & 1.36 & 5.14 \\
\hline 5 & $\mathrm{Al}$ & 0.52 & 0.30 \\
\hline
\end{tabular}

Table 1

ELEMENTAL COMPOSITION $\mathrm{OF} \mathrm{ZrO}_{2}$

From the SEM images it is observed that after sintering, the sample surface morphology is composed of zirconia particles, with small defects of compactness. The particle size of $\mathrm{ZrO}_{2}$ is between $1 \div 3 \mu \mathrm{m}$.

The results on the mass evolution of the samples tested for degradation by immersion in artificial saliva in all predefined time intervals are centralized in table 2 . We find the presence of very small differences, ranging from 0.01 to $0.02 \mathrm{mg}$, which are in the analytical balance error range. Thus, it can be concluded that zirconia in sintered form does not undergo degradation processes in artificial saliva even after 21 days of immersion.

Following the immersion tests, the samples were investigated using the Phenom ProX electronic scanning microscope for a surface analysis to identify possible changes to the original morphology. The SEM images of the samples after the immersion test are shown in figures 4-8.

Among the materials widely used in general medicine and dentistry, zirconia combines high resistance, remarkable resistance to crack propagation, low thermal conductivity, high ionic conductivity, biocompatibility and chemical inertia [3, 5-8]. The transformation of the tetragonal phase into the monoclinic in the zirconia [9] results in increased resistance to degradation and increase of fracture resistance [6] of the material. This transformation mechanism makes zirconium the strongest and most fracture resistant material of all ceramic biostructures [10-12].

Over the last thirty years, zirconia has been used in restorative dentistry for the manufacture of dental implants and abutments [13]. Over the past twenty years, zirconia has been used as a substrate for making crowns and dental bridges in the lateral area $[5,6,10,14]$. Recently, colored zirconia and improved translucency have been developed to have a close look at human dentition [15]. This new material has a bending strength of 900-1400 MPa and a breaking strength of up to $6 \mathrm{MPa} \mathrm{m} 1 / 2$ [16]. Such advantages have led to an exponential increase in the use of zirconia for monolithic crowns and dental bridges in the posterior region [17] of the dental arches.

Choosing an ideal aesthetic material for dental restorations is a major desideratum in dentistry and necessity for improvement of the materials has led to a significant change in available materials and usage techniques [18].

In the case of use of zirconia for making medical and dental devices, the material must be treated on the surface to obtain not only mechanical functions such as wear

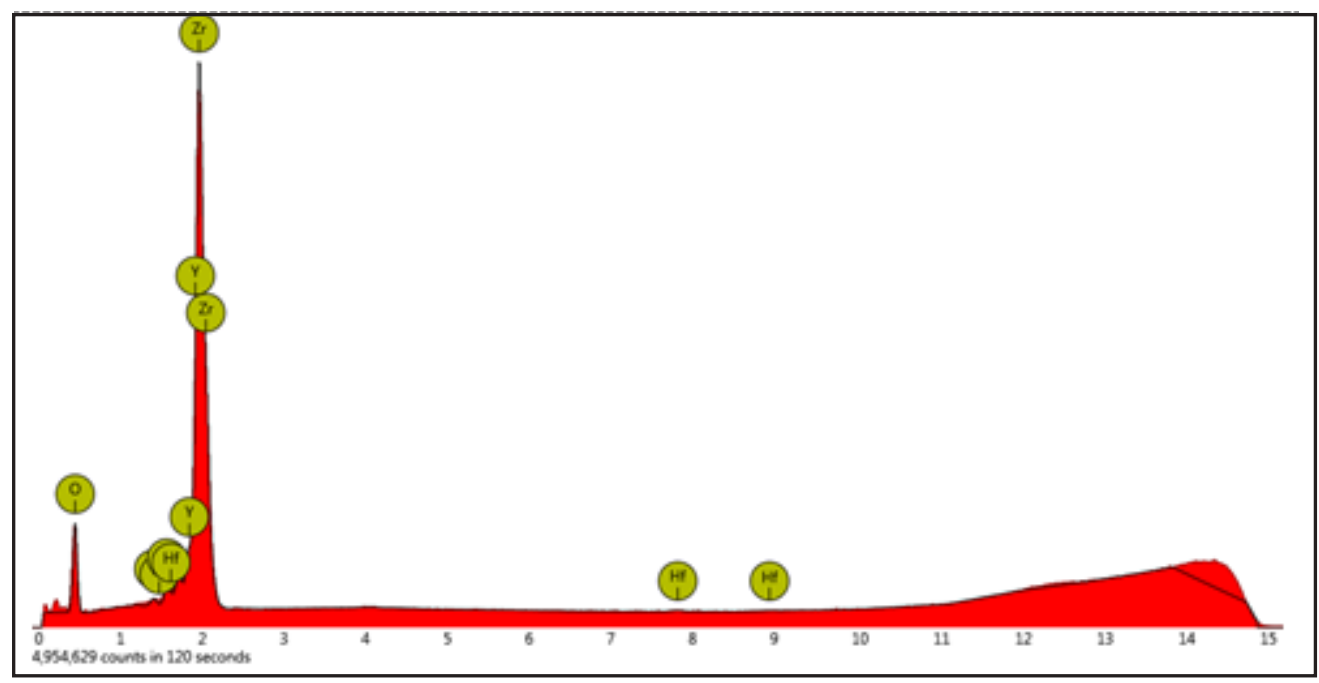

Fig. 2.The EDS spectrum of the studied $\mathrm{ZrO}_{2}$ sample

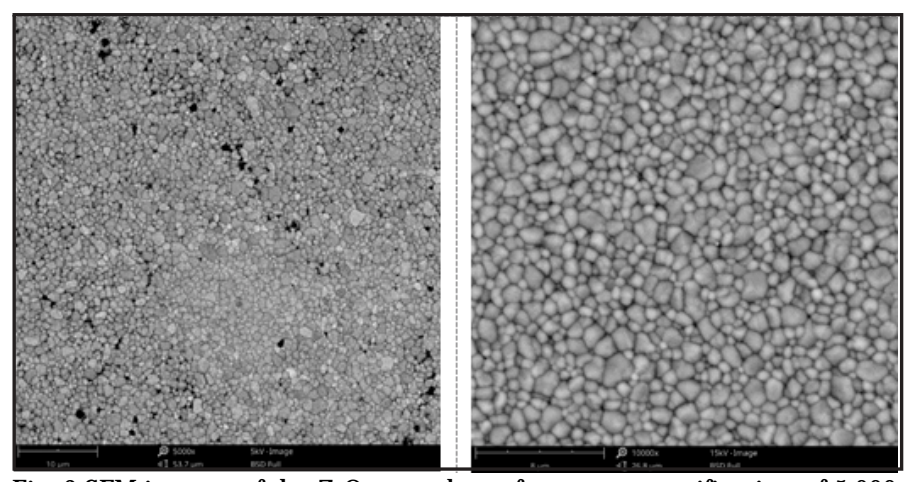

Fig. 3.SEM images of the $\mathrm{ZrO}_{2}$ sample surface at a magnification of $5.000 \mathrm{x}$ (left) and at a magnification of $10.000 x$ (right)
Table 2

VARIATION OF EXPERIMENTAL SAMPLE MASS AFTER IMMERSION TEST IN ARTIFICIAL SALIVA

\begin{tabular}{|c|c|c|c|c|}
\hline No & Period & \multirow{2}{*}{ Material } & $\begin{array}{c}\Delta \mathrm{m} \\
{[\mathrm{mg}]}\end{array}$ & SD \\
\hline 1 & Day1 & & 0.02 & 0.01 \\
\hline 2 & Day 3 & & 0.01 & 0.01 \\
\hline 3 & Day 7 & \multirow{2}{*}{$\mathrm{ZrO}_{2}$} & -0.02 & 0.01 \\
\cline { 1 - 1 } \cline { 4 - 4 } & & -0.01 & 0.01 \\
\hline 5 & Day 14 & -0.02 & 0.01 \\
\hline
\end{tabular}



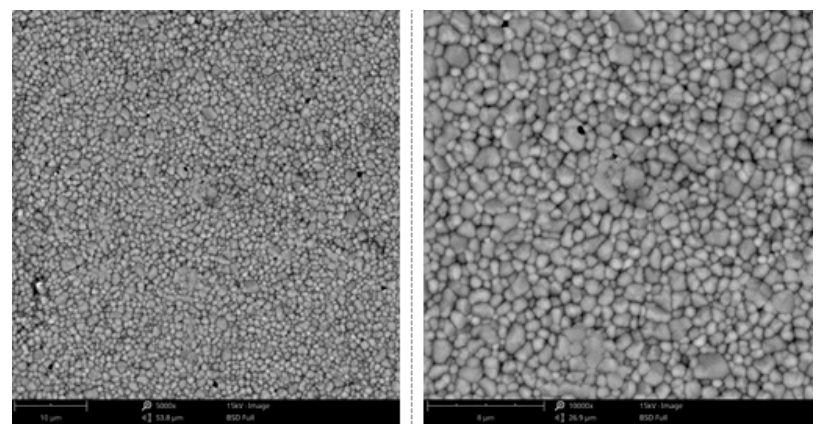

Fig. 4.SEM images of the $\mathrm{ZrO}_{2}$ sample surface at a magnification of $5.000 \mathrm{x}$ (left) and a magnification of 10.000x (right) after immersion for one day in artificial saliva

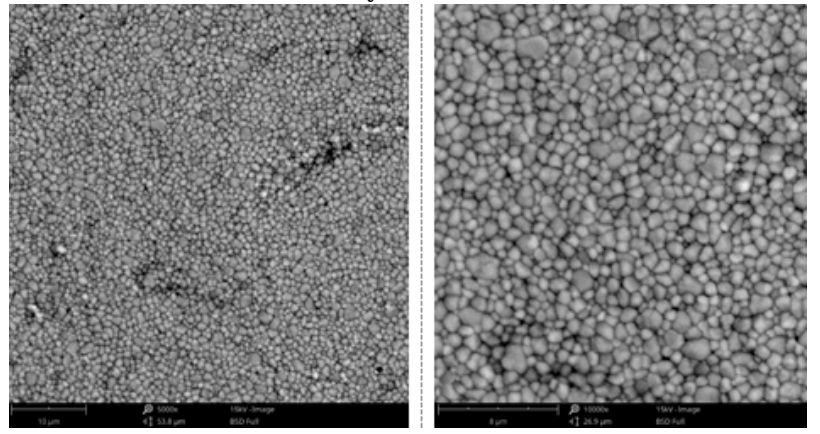

Fig. 5.SEM images of the $\mathrm{ZrO}_{2}$ sample surface at a magnification of $5.000 \mathrm{x}$ (left) and a magnification of $10.000 \mathrm{x}$ (right) after immersion for 3 days in artificial saliva
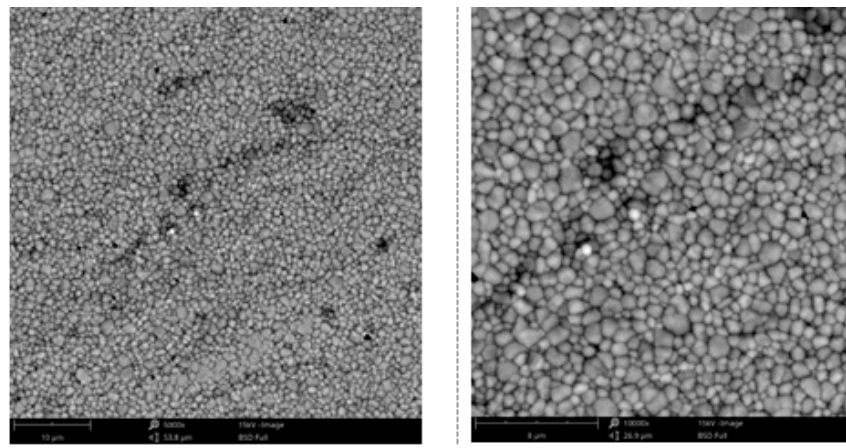

Fig. 6.SEM images of the $\mathrm{ZrO}_{2}$ sample surface at a magnification of $5.000 x$ (left) and a magnification of $10.000 x$ (right) after immersion for 7 days in artificial saliva

resistance but also biomedical capabilities such as cell adhesion and bacterial decolonization [15].

\section{Conclusions}

By SEM examining of samples prior to immersion in artificial saliva we found that the material contained strictly the chemical elements specified by the manufacturer.

SEM examination and mass evaluations performed after immersion in artificial saliva demonstrate that the material did not suffer degradation processes, the minimum differences in the measurements being within the analytical balance weighing range.

\section{References}

1.OSMAN RB, SWAIN MV, A Critical Review of Dental Implant Materials with an Emphasis on Titanium versus Zirconia, Materials 2015, 8, 932-958; doi:10.3390/ma8030932.

2.LAWSON S. Environmental degradation of zirconia ceramics. J. Eur. Ceram. Soc. 1995, 15, 485-502.

3.CHEVALIER J. What future for zirconia as a biomaterial? Biomaterials 2006, 27, 535-543.

4.ATT W, GRIGORIADOU M, STRUB JR, ZrO2 three-unit fixed partial dentures: Comparison of failure load before and after exposure to a mastication simulator. J. Oral Rehabil. 2007, 34, 282-290.
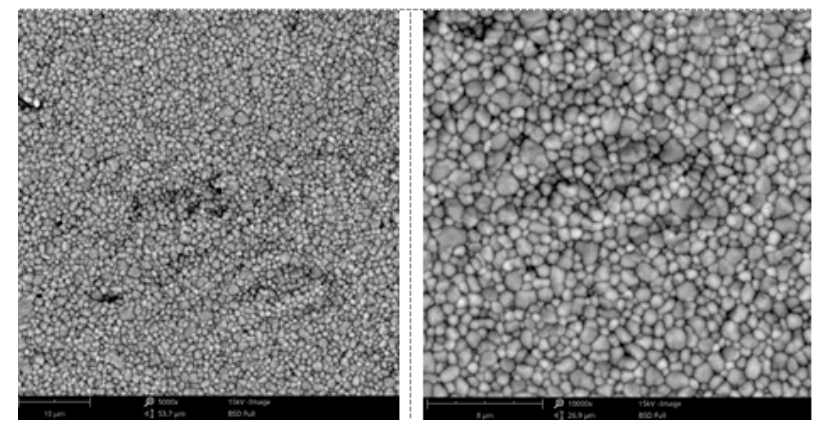

Fig. 7.SEM images of the $\mathrm{ZrO}_{2}$ sample surface at a magnification of $5.000 x$ (left) and a magnification of 10.000x (right) after immersion for
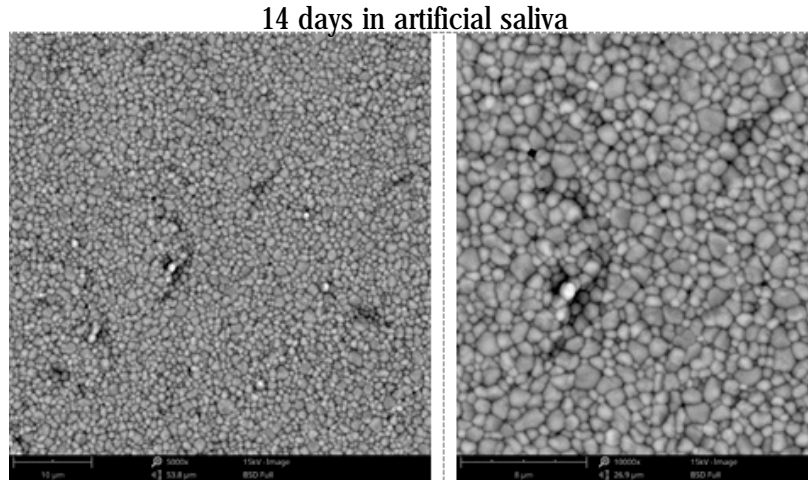

Fig. 8.SEM images of the $\mathrm{ZrO}_{2}$ sample surface at a magnification of 5.000x (left) and a magnification of 10.000x (right) after immersion for 21 days in artificial saliva

5.MIYAZAKI T, NAKAMURA T, MATSUMURA H, BAN S, KOBAYASHI T. Current status of zirconia restoration. J Prosthodont Res 2013;57:23661.

6.DENRY I., KELLY J . R., State of the art of zirconia for dental applications, Dent. Mater., Vol. 24, No. 3, p. 299 - 307, ISSN 0109-564, 2008.

7.ABDUO J, LYONS K, SWAIN M. Fit of zirconia fixed partial denture: a systematic review. J Rehabil 2010;37:866-876.

8.YIN L, SONG XF, SONG YL, HUANG T, LI J. An overview of in vitro abrasive finishing and $\mathrm{CAD} / \mathrm{CAM}$ of bioceramics in restorative dentistry. Int J Mach Tool Manu 2006;46:1013-1026.

9.GARVIE RC, NICHOLSON PS. Phase analysis in zirconia systems. J Am Ceram Soc 1972;55;303-305.

10.DENRY I, KELLY J R. Emerging ceramic-based materials for dentistry. J Dent Res 2014;93:1235-42.

11.CHEVALIER J, GREMILLARD L, VIRKAR AV, CLARKE DR. The tetragonalmonoclinic transformation in zirconia: lessons learnt and future trends. J Am Ceram Soc 2009;92:1901-1920.

12.EVANSAG, CANNON RM. Toughening of brittle solids by martensitic transformations. Acta Met 1980;34:761-800.

13.MANICONE PF, IOMMETTI PR, RAFFAELLI L. An overview of zirconia ceramics: basic properties and clinicla applications. J Dent 2007;35:819-826.

14.BAN S. Reliability and properties of core mateirals for all-ceramic dental restoratons. J pn Dent Sci Rev 2008;44:3-21.

15.YINA L, NAKANISHIB Y, ALAOA AR, SONGC XF, ABDUOD J , ZHANG $Y$, A review of engineered zirconia surfaces in biomedical applications, Available online at www.sciencedirect.com, doi: 10.1016/ j.procir.2017.04.057, Procedia CIRP 65 (2017) 284 - 290.

16.ZHANG Y. Making yttria-stabilized tetragonal zirconia translucent. Dent Mater 2014;30:1195-1203.

17.ZHANG Y, LEE JJW, SRIKANTH R, LAWN BR. Edge chipping and resistance of monolithic ceramics. Dent Mater 2013; 29: 1201-1208.

18.EARAR, K., GRIGOROIU, R., SCUTARIU, M.M., VASILE, E., ANTONIAC, A., DRAGOMIR, L., GRADINARU, S., Effect of the Sandblasting Process on the Surface Properties of Dental Zirconia, Rev Chim. (Bucharest), 68, no. 7, 2017, p. 1560-1564

$\overline{\text { Manuscript received: } 4.07 .2018}$ 